\title{
Research on the Selection of the Third Party Logistics' Distribution Center
}

\author{
Wang Ke \\ School of Economic and Management \\ Shengyang Aerospace University \\ Shengyang China
}

\begin{abstract}
The third party logistics enterprise in the site planning and design of the distribution center occupies an important position in the logistics network system, which belongs to the strategic item in logistics system researches. The choice of logistics distribution center makes a significant influence on its actual business cost and efficiency, which also affects the development and expansion of its storage scale in the future. It is a strategic problem and lies in all levels of the logistics system. The research to the selection of logistics distribution center is of great practicality.The influence factors and the basic principles have been analyzed after introduction on the concept of the third party logistics, distribution center, and other relevant theoretical knowledge. On the base of the constructing of the evaluation index system about logistics distribution center, this article proposes the fuzzy comprehensive evaluation method. We give an evaluation on the third party logistics distribution center after taking factors such as transport environment, social and economic benefits, natural environment and policy environment into account together effectively.
\end{abstract}

Keywords-the third party logistic, distribution center, site selection, the fuzzy comprehensive evaluation method

\section{INTRODUCTION}

With the continuous improvement of the market economy, as well as further competition in the market, enterprises have focused on their own core technology development and management in order to enhance the competitiveness by outsourcing the storage, transportation and other operations to professional third-party logistics companies after product off the assembly line, which provides a good environment for third-party logistics management and distribution technology, and achieves the optimal allocation of resources, as well as improves the operational efficiency of enterprises.

Due to the increasingly prominent status of third-party logistics in the national economy, third party logistics logistics centers as a sub-node of distribution has began to caught attention. Third-party logistics distribution center site occupies an important strategic position in the planning and design of distribution centers. To some extent, whether its location is reasonable or not largely determines the overall efficiency of the logistics network. To maximize economic benefits of logistics distribution center in the modern circulation of commodities, an important question is how to do siting of third party logistics distribution center so as to reduce the total cost of logistics.

\section{A THIRD-PARTY LOGISTICS AND DISTRIBUTION CENTER OVERVIEW}

\section{A. Third-party logistics overview}

Third-party logistics is to outsource all or part of the enterprise logistics management tasks to specialized companies, and those who can provide customers with a wide range of professional logistics services company are called third-party logistics service providers. It refers to a logistics operation and management when the production and operation enterprises concentrating their efforts on the core business, and in the manner of the contract entrusting the original logistics activities of their own to the professional logistics services company, while maintaining close contact through information systems with logistics services company, in order to achieve the logistics management and control of the whole. With the continuous development of logistics technology, third-party logistics as an effective means of improving material flow speed, saving storage costs and capital costs in transit, has increasingly attracted people's attention.

\section{B. An overview of distribution centers}

Distribution centers refers to the facilities and institutions who receive and process the end-user orders information, sorting many varieties of goods transported from upstream, processing, grouping and delivery according to customer requirements. In the entire logistics system, the distribution center is the material and technical basis of modern e-commerce activities to carry out distribution activities, which is connected to supply points and demand points, occupies an important position as a hub, and plays a connecting role. Distribution center with optimal solution can effectively save costs, promote coordination and cooperation of production and consumption, ensure the balanced development of the logistics system and overall effectiveness. Therefore, it is necessary to conduct comprehensive scientific and rational analysis by a siting principle and mathematical model in site planning of logistics distribution center.

\section{THE LOGISTICS DISTRIBUTION CENTER SITING ANALYSIS}

With the continuous development of the logistics network systems, logistics and distribution center as a node of logistics network, largely determines the overall efficiency of the logistics network by its reasonableness of location. Currently, efforts to reducing costs, increasing 
corporate profits, have become an important guarantee to the logistics business survival, increasing development potential and remaining competitive. Therefore, a reasonable logistics center location is very important.

\section{A. General principles of logistics distribution center location followed by}

Logistics center in the logistics system has a very important position, which is the bridge connecting upstream and downstream of logistics; and logistics center, once completed it will be difficult to do major changes that are related to the level of operating costs, efficiency, and control of logistics. Therefore, in the planning and design, we must effectively control the following four design principles:

adaptability principle: logistics center siting must adapt to national, provincial economic development policies and regulations, to our distribution and logistics resources, to the needs of the distribution, as well as to the national economic and social development.

coordination principle: logistics and distribution center includes including the purchase of storage operations management, custody operations management, picking operations management, distribution and processing operations management, database operations management and information systems management. How to make a very balanced and coordinated operation between them is extremely important.

economy principle: In the fierce market competition, the users will hold higher requirements on the timely distribution and low rate of out of stock. When meeting the high quality services, the siting must also consider the logistics costs.

strategic principle: location of logistics center should have a strategic vision. Whether it's construction facilities planning, choice of machinery and equipment, or the design of information processing systems, it must take into account the strong adaptability, high degree of flexibility to accommodate the increasing logistics volume, and expanding scope of business .

\section{B. Factors analysis on logistics distribution center location decision}

The main distribution center location should consider the following factors:

\section{1) transportation environment}

Roads, communications and other infrastructure situation of the city, as well as electricity, water, heat, gas supply capacity, are the factors to be considered by distribution centers; transport condition is one of the important factors affecting the cost and efficiency of logistics: distribution centers should be equipped with convenient transportation conditions, preferably being close to transportation hubs, with proper convergence to the roads, railways, ports and airports in order to ensure timely and accurate delivery service. Transportation inconvenience will directly affect the efficiency and satisfaction of logistics services, and therefore the siting must consider external transport transport pathways, as well as the future traffic situation and development of the surrounding area and other factors.

2) social and economic benefits
Preferential policies for logistics industry in the region of distribution center will bring the economic benefits: lowering logistics costs, sufficient quantities and high quality workforce and suppliers, distributors, customers and their needs, degree of utilization for modern logistics facilities, as well as maximized efficiency, high-quality customer service levels are to be taken into considerations for distribution center location .

\section{3) the natural environment}

Prior knowledge of the local natural environment helps reduce construction risk; during selection process of distribution center site, the main considerations include meteorological conditions, hydrological conditions, geological conditions and terrain conditions.

\section{Feasibility Study of distribution center location scheme}

Construction of distribution centers, especially in the construction of large distribution centers, needs a largescale investment; after determining the siting program, you also need to demonstrate the feasibility of the program to see if it is feasible. Typically, the main argument is analyzed in terms of the total cost, unit cost, the payback period, the investment profit margin of distribution centers,

In evaluating the logistics distribution center location, we should follow the principles of sustainable urban development, as well as the principles of sustainable development of logistics and distribution center after the completion, so as to leave enough space for long-term development. However, the siting factors described above do not apply to all of the logistics distribution center locations; factors considered by different companies are different. Therefore, enterprises in logistics and distribution center site selection should combine their own development strategies to develop an appropriate site selection criteria:

\section{THE FUZZY COMPREHENSIVE EVALUATION METHOD}

Currently there are many ways to logistics center location siting, which can be divided into two major categories: quantitative and qualitative.

Because the third-party logistics distribution center location evaluation is a comprehensive evaluation related to many factors, evaluation of the distribution center location often can not point to a specific numerical point perform but to represent by the respective merits of the grade. Therefore, conventional statistical methods are difficult to deal with, while fuzzy comprehensive evaluation method combines quantitative and qualitative methods, and carries out a comprehensive evaluation of the system; it is better able to handle multiple factors, high subjective judgment and fuzziness high that people can not clearly give the exact mathematical description; fuzzy comprehensive evaluation method is suitable for study the problem of logistics distribution center location .

\section{A. Identification model of the fuzzy comprehensive evaluation}

$$
U=\left\{u_{1}, u_{2}, \Lambda, u_{n}\right\}
$$

according to the purpose of the evaluation to determine the set of evaluation factors 
To evaluate a program, if there are $\mathrm{n}$ evaluation index factors, denoted by..., then the $\mathrm{n}$ evaluation factors constitute a set of evaluation factors.

to give the rating scale collection

According to the actual need, to divide the review into $\mathrm{m}$ grades, denoted by..., these constitute a comment finite set based on reviews.

to determine the weight of each evaluation factor

In fuzzy sets..., $W_{i}$ is the weight amount assign to factor $U_{i}$, namely the weight of each factor reallocation vector. From $\mathrm{U}$ to $\mathrm{V}$ a fuzzy mapping $\mathrm{R}$ vector.... is called single factor assessment, which is the fuzzy subset of $\mathrm{V}$, where: $0 \leq \leq 1$ represent the factor..... that can be awarded as....membership. all vectors of the fuzzy mapping $\mathrm{R}$ in juxtaposition will bring a single factor evaluation matrix called a comprehensive assessment of the transformation matrix.

$$
R=\left(\begin{array}{cccc}
r_{11} & r_{12} & \cdots & r_{1 n} \\
r_{21} & r_{22} & \cdots & r_{2 n} \\
\vdots & \vdots & \vdots & \vdots \\
r_{m 1} & r_{m 2} & \cdots & r_{m n}
\end{array}\right)
$$

use fuzzy matrix composite calculation ... for a fuzzy comprehensive evaluation

$$
S=W \circ R=\left(\mu_{1}, \mu_{2}, \cdots, \mu_{m}\right) \circ\left(\begin{array}{cccc}
r_{11} & r_{12} & \cdots & r_{1 n} \\
r_{21} & r_{22} & \cdots & r_{2 n} \\
\vdots & \vdots & \vdots & \vdots \\
r_{m 1} & r_{m 2} & \cdots & r_{m n}
\end{array}\right)=\left(s_{1}, s_{2}, \cdots, s_{n}\right)
$$

Where "o" is fuzzy composite operator.

There are four common fuzzy matrix composite calculation methods:

The ......operator,

$s_{k}=\bigvee_{j=1}^{m}\left(\mu_{j} \wedge r_{j k}\right)=\max _{1 \leq j \leq m}\left\{\min \left(\mu_{j}, r_{j k}\right)\right\}, \quad k=1,2$,

$$
M(\bullet, \vee) \text {, }
$$

The ......operator,

$$
s_{k}=\bigvee_{j=1}^{m}\left(\mu_{j} \cdot r_{j k}\right)=\max _{1 \leq j \leq m}\left\{\mu_{j} \cdot r_{j k}\right\}, \quad k=1,2, \Lambda, n
$$

$$
M(\wedge, \oplus)
$$

The ......operator,

$$
s_{k}=\min \left\{1, \sum_{j=1}^{m} \min \left(\mu_{j}, r_{j k}\right)\right\}, \quad k=1,2, \Lambda, n
$$

$M(\bullet, \oplus)$

(4) The ......operator,

$$
s_{k}=\min \left(1, \sum_{j=1}^{m} \mu_{j} r_{j k}\right), \quad k=1,2, \Lambda, n
$$

E. Conclusion Analysis:

Finally, a comprehensive analysis of fuzzy evaluation vector $\mathrm{S}$ concludes. Generally there are following three methods:

The principle of maximum membership

$$
M=\max \left(S_{1}, S_{2}, \cdots, S_{n}\right)
$$

The weighted average principle

$$
u^{*}=\frac{\sum_{i=1}^{n} \mu\left(v_{i}\right) \cdot s_{i}^{k}}{\sum_{i=1}^{n} s_{i}^{k}}
$$

Single-valued fuzzy vector

$$
c=\frac{\sum_{i=1}^{n} c_{i} \cdot s_{i}^{k}}{\sum_{i=1}^{n} s_{i}^{k}}
$$

Through the integrated use of these three methods, we can get fuzzy comprehensive evaluation of the program's final score, hence to arrive at the most satisfactory thirdparty logistics distribution center location.

\section{B. The application step}

to determine the object selected, establish third-party logistics distribution center location enterprise evaluation index set........;

to determine the reviews set.......;

to establish index layer for each evaluation factors, the overall evaluation matrix......... and evaluation of each index layer corresponding to evaluation factors judgment matrix........;

, to determine indicators relative to the overall objective of the combination weights;

to conduct single factor evaluation, and obtain transformation matrix.....;

to perform two fuzzy evaluation on ..........;

through fuzzy comprehensive evaluation, to calculate a third party logistics distribution center location composite score; for $\mathrm{S}$ values of each alternative third-party logistics distribution center location point, through the weighted average method to sort by size, and choose the maximum $S$ for the most advantageous one.

\section{CONCLUSION}

Choose a reasonable logistics distribution center is very important, through the construction of logistics nodes, forming the radiation of the road, rail, maritime, air transport system in whole China; first, to occupy a competitive advantage in terms of speed, cost; moreover, to build large logistics distribution center in marina and transportation hubs and major ports, forming a national chain logistics network, so that the logistics in the region and between regions tend to be reasonable, and the rational distribution adapting to the production can reduce two-way 
flow of raw materials, finished goods between the origin and the point of consumption, hence improving logistics services quality, reducing logistics time, and improving logistics efficiency.

Appropriate logistics distribution center siting could ensure the timely and accurate delivery, as well as the stability and reliability of the logistics supply chain and customer service; it can not only improve the operational efficiency of the logistics system, reduce logistics costs, but also improve customer service satisfaction of the entire supply chai, promote the improvement of logistics industry itself, and therefore have very far-reaching significance for the study of third-party logistics distribution center location selection.

\section{REFERENCES}

[1] Wang Jian. Yu Chengfeng. Research on dynamic evaluation method of logistics center location [J]. Highway and Transportation Research, 2007. (10)

[2] Xu Sanyou, Liu Jing. Logistics Center Location and Case Analysis [J]. Logistics Technology, 2006, (07).
[3] Sun Liang, Wang Xiaoxia, Zheng Jichun. Logistics center site evaluation system design [J]. Logistics Technology, 2006, (10) :6267.

[4] Dong Yanping. Logistics distribution center siting study based on fuzzy analytic hierarchy process. [J]. Technology start-ups, 2010, (10) :102-106

[5] Ding Liqun, Li Yongzhou.Logistics distribution center based on fuzzy evaluation - take Wuhan Iron Yitong logistics company as an example [J] Logistics Engineering and Management, 2009, (12).

[6] Li Yaru, Zhang Qingnian. Evaluation methods of planning logistics center location [J]. Highway and Transportation Research, 2010.02

[7] Wang Ling, Li Huifang. Study of logistics center location based on fuzzy comprehensive evaluation of. [J]. Railway freight, 2008 , (11) :11-14

[8] Yu Wenjin, LIU Kai. The Study on Logistics Center Location Based on ANP

[9] [J] . Journal of Transportation Systems Engineering and Information Technology, 2006,(5):123-126.

[10] Chen-YC.An application of fuzzy set theory to the external performance

[11] Evaluation of distribution centers in logistics [J].Soft Computing, 2002, (6). 